\title{
Agricultural and biomedical application of Silver Nanoparticles synthesized by Halimeda gracilis Harvey ex J. Agardh
}

\author{
Suparna Roy*, P. Anantharaman \\ Centre of Advanced Study in Marine Biology, Faculty of Marine Sciences, Annamalai University, Parangipettai, Tamilnadu, \\ India. \\ *Correspondence: suparna09roy@gmail.com
}

\begin{abstract}
The present work is focused on the biosynthesis of the Silver (Ag) Nanoparticles using an aqueous extract of the green seaweed Halimeda gracilis. The visible colour change indicated the biosynthesis of Silver Nanoparticles and the specific peak produced within the UV-Vis spectrum confirmed the biosynthesis of Silver Nanoparticles. The possible functional groups were identified with Fourier Infrared Spectroscopy. The morphological characterization of biosynthesized Silver Nanoparticles was done by Scanning Electron Microscopy and Dynamic light scattering measurements and Zeta potential. The average size distribution of AgNanoparticles were 295.9 (d.nm) and fairly stable with a zeta potential value of $-28.6 \mathrm{mV}$. The size of biosynthesized Ag-Nanoparticles was also measured with $X$-ray diffraction assay. Due to agglomeration, the size difference of biosynthesized Ag-Nanoparticles in case of SEM and EDX occurred. The biosynthesized AgNanoparticles were assayed for their antibacterial activity against some human pathogens and for their potential on seed germination of Abelmoschus esculentus and Raphanus sativus var. longipinnatus. The antibacterial activity of biosynthesized Ag Nanoparticles was the highest against Proteus mirabilis $(2.33 \pm 0.2 \mathrm{~cm})$, followed by Klebsiella pneumoniae, $(1 \pm 0.0 \mathrm{~cm})$. The effect of biosynthesized Ag-Nanoparticles on the seed germination of Raphanus sativus var. longipinnatus was excellent as the germination rate was 100 percent for AgNanoparticles treated seeds, which was better than normal seaweed extract and seaweed liquid fertilizer treated seeds. The seed germination was also good for Abelmoschus esculentus with the treatment of seaweed mediated Ag-Nanoparticles as germination rate was 60 percent. This work proved that seaweed synthesized AgNanoparticles are Phyto-friendly in nature and in future nano-bio fertilizer may be used as the growth promoter and eco-friendly Nano-bio-fertilizer.
\end{abstract}

Keywords- Green synthesis, seaweed, Silver nanoparticles, seed germination, antibacterial activity.

\section{INTRODUCTION}

The drug resistance is a serious medical problem, as the strains are rising fast and mutated consequently, so the treatment of some diseases such as diarrheal diseases, malaria, Urinary tract infections and Tuberculosis (TB) required the new drugs. The pathogenic bacteria due to their multidrug resistance properties, they are gradually becoming resistant against many market available antibiotics. It may be due to uncontrolled and improper applications of various antibiotics, which resulted multidrug resistant bacteria (Manikandan et al. 2011). Some resistant strains such as Vancomycin Resistant Enterococci (VRE) (Gold, 2001), extended Spectrum Beta lactamase resistant Enterococci (Bhattacharya, 2006) had been reported previously. So, there is need to find out the better antibacterial compounds. Some seaweed compounds had been reported as antimicrobial agents (Pérez et al. 2016) but all seaweeds are not yet assayed for their bactericidal effect, likewise silver nanoparticles from some seaweeds had also been reported for its antimic robial activity (Ku mar et al. 2013, Gandhi et al. 2016, and Vivek et al. 2011). The major problem in agriculture is the use of chemical fertilizer, which gradually increased the chemical toxic effect in the soil by destroying the soil quality and also effecting on the production of crops and vegetables. Now a day, seaweeds were used as bio-fertilizer to save the environment by practicing organic farming, the effect of liquid fertilizer of Stochiospermum marginatum was analysed to brinjal plants which revealed promoting effect on growth and productivity of brinjal plants (Sivasangari Ramya et al. 2015). So, on the basis of the mentioned problem, I selected Halimeda gracilis for synthesis of Silver nanoparticles synthesized and investigated for its bactericidal effect and the potential for seed germination. This green seaweed and its mediated Silver nanoparticles, not yet investigated for the above mentioned applied fields for its applications. 


\section{MATERIALS AND METHODS}

Biosynthesis of Silver Nanoparticles:

Seaweed extracts preparation:

The fresh seaweed Halimeda gracilis had been collected from Olaikuda $\left(09^{\circ} 18.309^{\prime} \mathrm{N}\right.$ and $\left.079^{\circ} 20.076^{\prime} \mathrm{E}\right)$, Rameshwaram (Fig. 1), southeast coast of India. Seaweed was identified with the standard taxonomic key of CMFRI. It was washed with in-situ sea water and distilled water thrice. Then, $20 \mathrm{gm}$ of seaweed Halimeda gracilis (Fig. 2) was cut into very small pieces and ground to make it powder and was dissolved in $100 \mathrm{ml}$ of distilled water and boiled for 10 minutes. The crude extract of seaweed was filtered with Whatman No. 1 filter paper and repeatedly filtered with a thin layer of cotton to get the clear seaweed extract. This crude seaweed extract was stored in $4^{\circ} \mathrm{C}$ for further use.

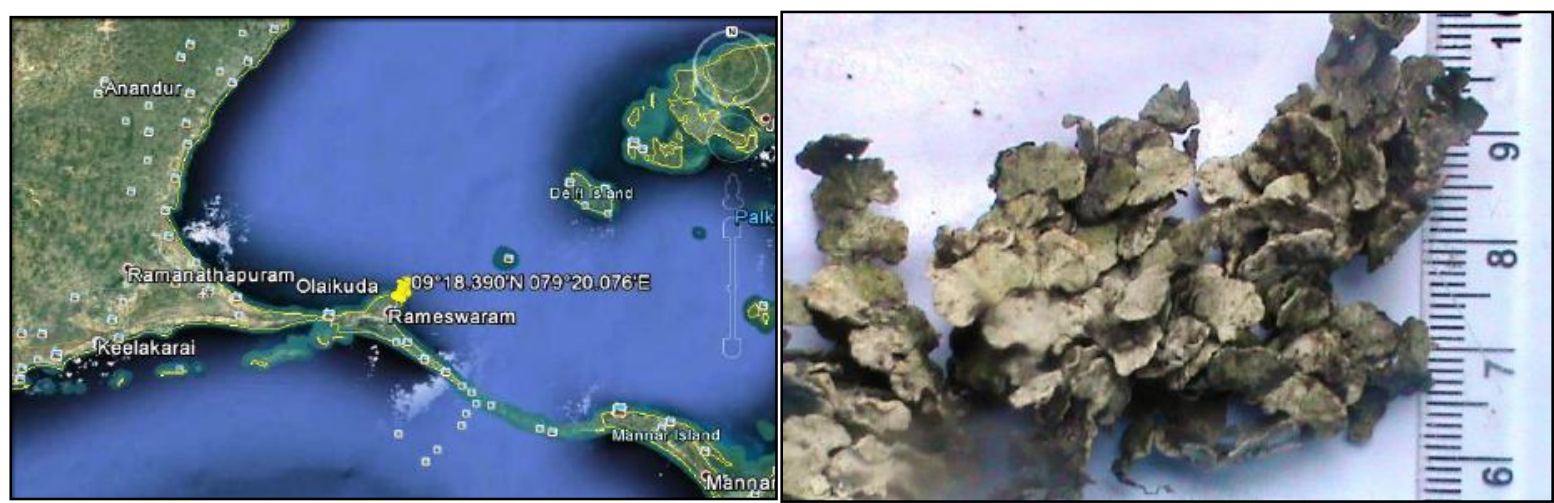

Fig 1: Map showing the sampling location. Fig 2: Halimeda gracilis, (Division-Chlorophyta, Class-Chlorophyceae, and Family - Halimedaceae)

\section{Preparation of seaweed extract:}

The collected seaweeds were washed repeatedly to properly clean for further use. The fresh cleaned seaweeds were cut into small pieces and grinded in mortar and pastel to make as paste, and then mixed well with 100 $\mathrm{ml}$ distilled water. The mixture was boile $\mathrm{d}$ in water bath for 10 minutes. The solution was cooled and filtered and the filtrates were kept in freeze at $4^{\circ} \mathrm{C}$ for biosynthesis of Silver Nanoparticles.

Biosynthesis of Silver Nanoparticles:

The aqueous $1 \mathrm{mM} \quad \mathrm{AgNO}_{3}$ solution was prepared with distilled water mixed with silver nitrate powder. The $10 \mathrm{ml}$ seaweed extract as prepared above was taken and the Silver Nitrate solution of $90 \mathrm{ml}$ was mixed in a conical flux for biosynthesis of AgNanoparticles. The conical flux was placed in mechanical shaker at $120 \mathrm{rpm}$ for 72 hours at continuous shaking. The solution colour was gradually change to reddish brown to red which is may be due to biosynthesis of Silver Nanoparticles.

\section{Preparation of seaweed liquid bio-fertilizer:}

The $10 \mathrm{gm}$ of fresh chopped seaweed was boiled with $10 \mathrm{ml}$ of distilled water and boiled for 1 hour in water bath and this solution was filtered through muslin cloth. The solution was kept at room temperature to cool completely and solution was filtered with what man filter paper of pore size $20-25 \mu \mathrm{m}$ and the extracted seaweed liquid fertilizer was kept in $4^{\circ} \mathrm{C}$ freeze for future used.

Collection of seeds:

The market available seeds of ladies finger, Abelmoschus esculentus (L.) Moench, belong to family
Malvaceae and Raphanus sativus var. longipinnatus belong to family Brassicaceae were used for the present seed germination experiment.

Characterization of biosynthesized Silver Nanoparticles:

UV-Visible Spectrophotometer:

The biosynthesized Silver Nanoparticles after 3 days of shaking, distilled water and silver nitrate solution was scanned from $300 \mathrm{~nm}$ to $700 \mathrm{~nm}$ at spectrophotometer (SHIMADZU).

Fourier Transform Infrared (FT-IR) Spectroscopy:

The biosynthesized Silver Nanoparticles solution was made a pellet of dry powder, after drying of collected residue which was collected after centrifugation for 30 minutes at $5000 \mathrm{rpm}$. The adequate amount of dry powder of Silver Nanoparticles and powder $\mathrm{KBr}$ was mixed well to prepare pellet for analyse to FT-IR spectroscopy for the identification of possible functional groups present in the biosynthesized Silver Nanoparticles.

\section{Scanning Electron Microscopy:}

The scanning electron microscopic images were used for analysing the morphological structure of biosynthesized Silver Nanoparticles. The powder of biosynthesized Silver Nanoparticles sprayed on grid for preparation of a thin film and images were taken under

Dynamic Light Scattering (DLS):

The size distribution of Silver Nanoparticles was analysed by dispersed it in Milli-Q water, similarly zeta potential of solution of Silver Nanoparticles was measured by Malvern method. For measurement, the 
Silver Nanoparticles was dispersed in measurement cuvette and analysed for 60 seconds at room temperature.

XRD Measurements:

The dried biosynthesized Silver Nanoparticles were sprayed on measurement cuvette and measured under BRUKER D8 ADVANCE POWDER X-ray diffractometer. The samples were analysed from 20 to $80^{\circ}$ theta $(\theta)$ range and the operating voltage was $20 \mathrm{KV}$.

Test for potentiality for seed germination:

For surface sterilization of seeds, seeds were kept in 5\% Sodium hypochlorite solution for 15 minutes. Then, seeds were dipped in biosynthesized Silver Nanoparticles solution over night. The seeds were also kept in normal water for control treatment. In sterile Petri plate, one piece of sterile filter paper was placed which was wetted with biosynthesized Silver Nanoparticles, then all seeds were kept within Petri plates and $5 \mathrm{ml}$ of biosynthesized Silver Nanoparticles was added to the Petri plates. Then, seeds were incubated for 12 hours in room temperature. After germination of seeds, the seed germination parameters such as germination index, relative root elongation and relative seed germination along with the major parameters of seed germination i.e. seed germination percentage, seed germination rate and the mean seed germination time was calculated according to the standard equations used by Barrena et al., 2009; Thakkar et al. 2010 and Taga et al. 1984. The equations are as mentioned below.

Germination Percentage $(\mathrm{GP} \%)=(\mathrm{G} / \mathrm{n}) \times 100$

The $\mathrm{G}_{\mathrm{f}}$ in equation is representing the total number of germinated seeds within the complete experiment duration.

Mean Germination Time $(\mathrm{MGT})=\Sigma \mathrm{Ni} \mathrm{Di} / \mathrm{n}$

$\mathrm{n}=$ total seeds of experiment, $\mathrm{Ni}=$ at $\mathrm{i}^{\text {th }}$ day, the total germinated seed, and Di denoted as total number of the day at of experiment.

Germination Rate (GR) $=\Sigma \mathrm{Ni} / \Sigma \mathrm{Ti}$.

(3)

Where $\mathrm{Ni}$ is denoted total germinated seeds at time Ti.

$$
\mathrm{GR}=(\mathrm{a} / 1)+(\mathrm{b}-\mathrm{a} / 2)+(\mathrm{c}-\mathrm{b} / 3)+\ldots . .+
$$

(n-n-1/N)

Relative root elongation (E)

$$
=(\text { Mean root length with NPs }) / \text { (Mean }
$$

root length with control) $\times 100$

Germination index $(\mathrm{GI})$

$$
=(\text { Relative seed germination }) \times
$$

(Relative root elongation) / 100

Where, Relative seed germination

$=($ Seeds germinated with NPs $) /$ (Seeds germinated with control) $\times 100$
Antibacterial activity of bi osynthesized Silver Nanoparticles

Antibacterial assay:

Antibacterial activity of the biosynthesized Silver Nanoparticles using aqueous seaweed extracts of Chaetomorpha antennina, Chlorodesmis hildebrandtii, Halimeda gracilis, Amphiroa anceps, and Sargassum cinctum was assayed by agar disc diffusion method against six human pathogenic bacteria such as Klebsiella pneumoniae, Pseudomonas aeruginosa, Staphylococcus aureus, Escherichia coli, Enterococcus faecalis, and Proteus mirabilis which were collected from Department of Medical Microbiology, Raja Muthiah Medical College, Annamalai University. Each pathogen was taken from pure culture and inoculated into freshly prepared nutrient broth which was sub-cultured from pure culture. After 24 hours of culture, each bacterial culture was inoculated into the agar plates and kept for 24 hours. The market available Chloramphenicol antibiotic was used as positive control. The $500 \mathrm{mg}$ powder Chloramphenicol was dissolved in $100 \mathrm{ml}$ autoclaved distilled water to a concentration of $5 \mathrm{mg} / \mathrm{ml}$. The silver nitrate solution (1 $\mathrm{mM}$ ) was considered as negative control. The beads of filter paper were soaked with $20 \mu \mathrm{l}$ of antibiotic solution, silver nitrate solution and biosynthesized Silver Nanoparticles solution. The beads were placed in Petri plates with bacterial culture. The diameter of inhibitory zone was measured after 24 hours with technical measuring scale.

Statistical Analysis:

Each bacterial culture was inoculated in triplicates. The diameters of developed zone of inhibition were measured and from three zones of inhibitions, mean of zone of inhibition with standard deviation were measured.

\section{RESULTS AND DISCUSSIONS} Biosynthesis of Silver Nanoparticles from Halimeda gracilis Harvey ex J. Agardh and its effect on seed germination:

Biosynthesis and characterization of Silver Nanoparticles:

The change of colour from white to dark brownish of the mixed solution indicated the biosynthes is of Silver Nanoparticles (Fig. 3). The broad bend at 425 $\mathrm{nm}$ to $430 \mathrm{~nm}$ produced in UV-Visible spectrum confirmed the biosynthesis of Silver Nanoparticles (Fig. 4).

The SEM images, of seaweed synthesized Silver Nanoparticles indicated the presence of cubical, hexagonal and irregular shaped scatter and well distributed Nanoparticles with size less than $100 \mathrm{~nm}$ (Fig. 5). For aqueous extract of seaweed, the $3420.83 \mathrm{c} \mathrm{m}^{-1}$ bend 
indicated the presence of amine $(\mathrm{N}-\mathrm{H})$ groups. The alkenes groups may be present due to the broad bend at $1636.70 \mathrm{~cm}^{-1}$ and several peaks narrow peaks at 1507.76 $\mathrm{cm}^{-1}, 1522.23 \mathrm{~cm}^{-1}, 1541.26 \mathrm{~cm}^{-1}$ produced due to aromatic group $(\mathrm{C}=\mathrm{C})$ and nitro $(\mathrm{N}-\mathrm{O})$ group, amine group, and consequently the stretches at $1490.41 \mathrm{~cm}^{-1}$, $1458.09 \mathrm{~cm}^{-1}$ and $1384.06 \mathrm{~cm}^{-1}$ recorded the functional groups alkanes $(\mathrm{C}-\mathrm{H})$, aro matic $(\mathrm{C}=\mathrm{C})$ group, nitro $(\mathrm{N}-\mathrm{O})$ group, ester group. The stretches around $500 \mathrm{~cm}^{-1}$ to 400 $\mathrm{cm}^{-1}$ indicated the presence of alkyl halides (Fig. 6). The biosynthesized Silver Nanoparticles and the aqueous extract of seaweed were analysed for the characterization of their functional groups and their properties to FTIR Spectroscopy. For synthesized Silver Nanoparticles, the presence of bend at $3421.24 \mathrm{~cm}^{-1}$ indicated the presence of amine (N-H) group, $2924.25 \mathrm{~cm}^{-1}$ and $2851.32 \mathrm{~cm}^{-1}$ stretches reported the presence of alkanes $(\mathrm{C}-\mathrm{H})$ and aldehydes $(\mathrm{C}=\mathrm{O}),(\mathrm{C}-\mathrm{H})$ functional groups. The stretches at $1636.75 \mathrm{~cm}^{-1}, 1384.58 \mathrm{~cm}^{-1}, 1021.95 \mathrm{~cm}^{-1}$ and 527.63

Biosynthesis \& characterization of Silver Nanoparticles by

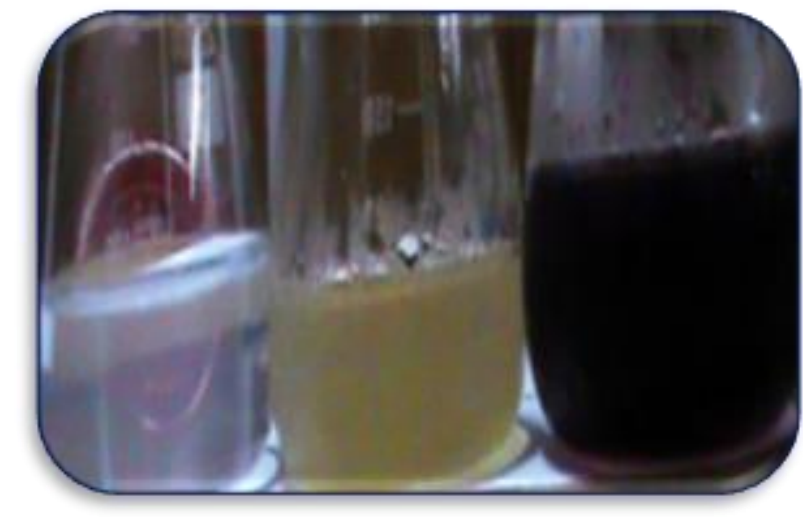

Fig. 3: Showing the biosynthesis of Ag-Nanoparticles from Halimeda gracilis.

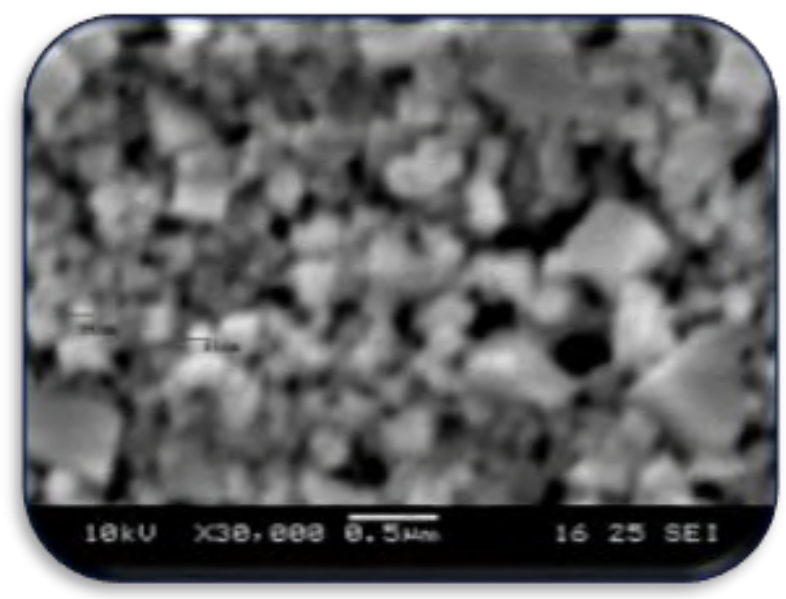

Fig. 5: Showing SEM image of biosynthesized AgNanoparticles. $\mathrm{cm}^{-1}$ was recorded the presence of alkanes $(\mathrm{C}=\mathrm{C})$ stretch, $\mathrm{N}-\mathrm{O}$ (nitro), ether, alkyl halides such as (C-I, C-Br) groups (Fig. 7). The peaks produced in $\mathrm{X}$-ray Diffractometer spectrum demonstrated the formation of hexagonal and cubical biosynthesized Silver Nanoparticles as the peaks have broader base and the narrower apex which indicated the presence of reduced crystal size Silver Nanoparticles. The observed peaks were found at $2 \theta$ values at $28.25^{\circ}, 32.10^{\circ}$ and $46.25^{\circ}$. The grain size (D) was $30.10 \mathrm{~nm}$. The equation used for analysis of the grain size as followed $-\beta=\pi / 180 \times$ width $(\mathrm{x}) ; \mathrm{D}=\mathrm{k} \lambda / \beta \cos \theta(\mathrm{nm})$ where $\mathrm{X}=0.21246,2 \theta=32.10^{\circ}$ (Fig. 8). The Z-average size distribution of $\mathrm{Ag}$ Nanoparticles was found $295.9 \mathrm{~d} . \mathrm{nm}$ and particles were well distributed in the water solution (Fig. 9). The zeta potential value of $\mathrm{Ag}$ Nanoparticles, (-28.6) $\mathrm{mV}$, indicated the high stability of Silver Nanoparticles (Fig.10).

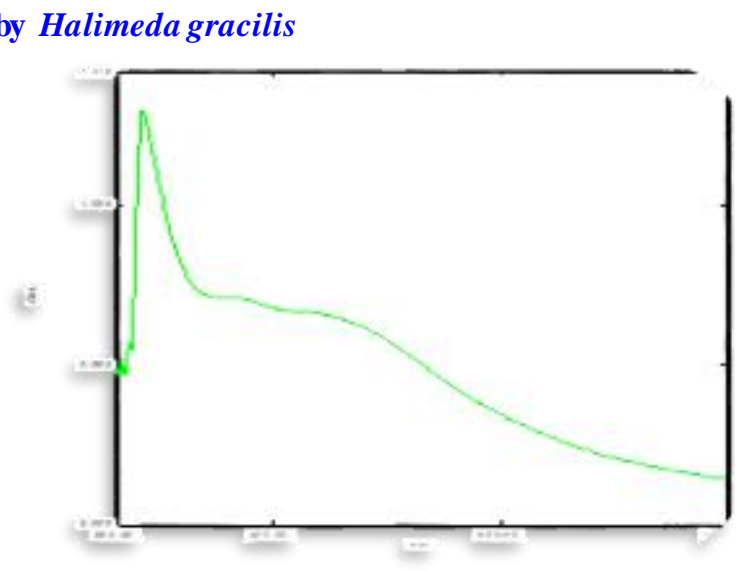

Fig. 4: Showing UV-Vis spectrum of biosynthesized Ag-Nanoparticles.

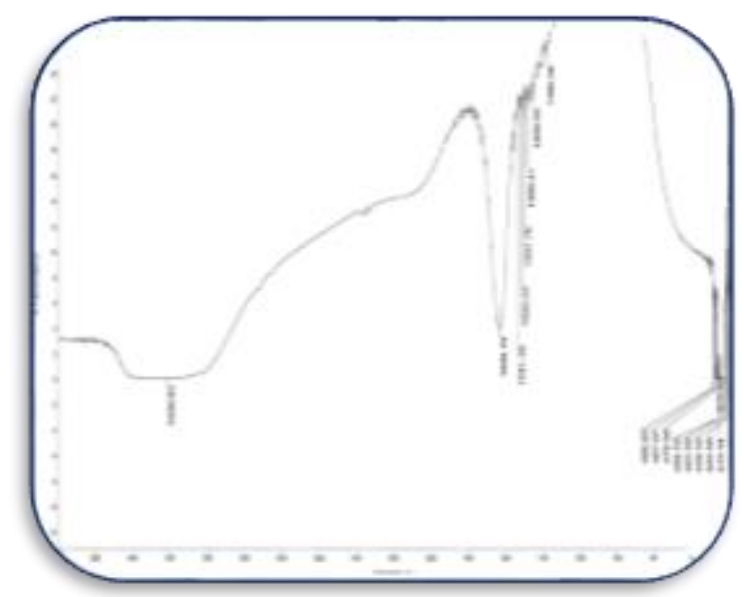

Fig. 6: Showing FT-IR spectrum of aqueous extract o of Halimeda gracilis. 


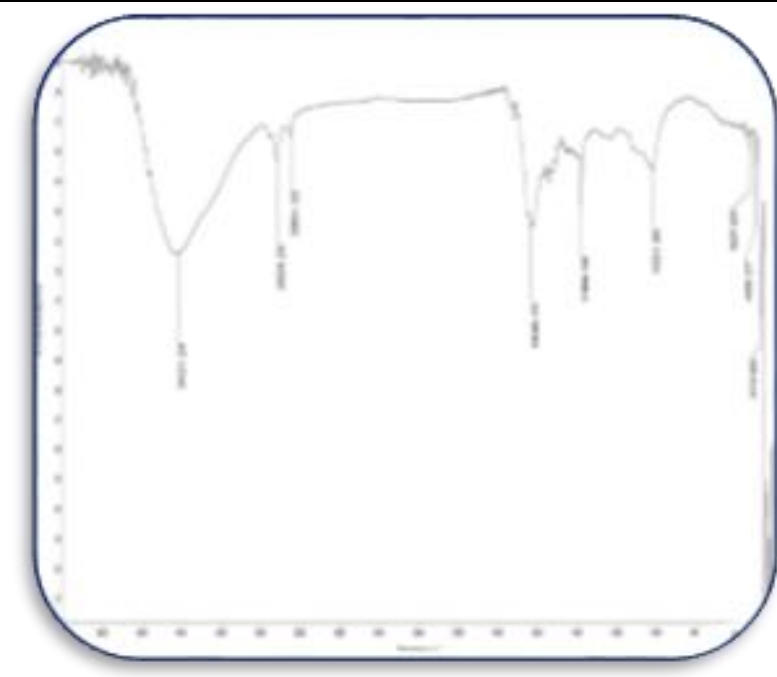

Fig. 7: Showing FT-IR spectrum of biosynthesized AgNanoparticles.

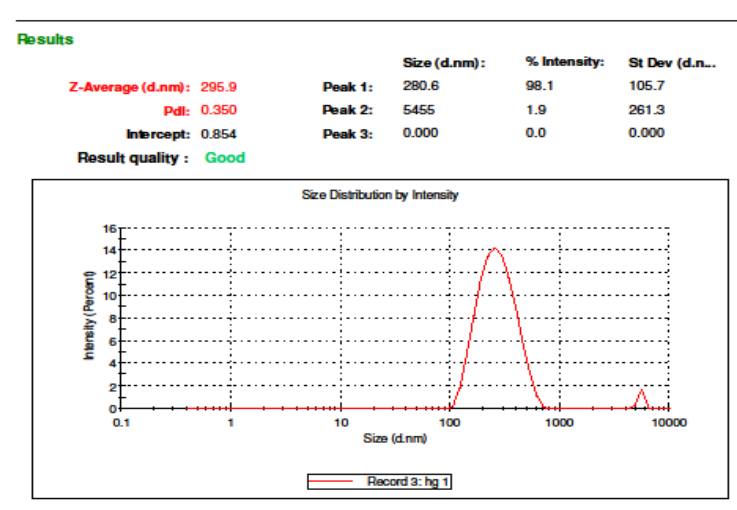

Fig. 9: Showing the size distribution of $\mathrm{Ag}$ Nanoparticles.

Effect of bi osynthesized Ag-Nanoparticles on seed germination of Abelmoschus esculentus:

The germination percentage of the seeds treated with Ag-Nanoparticles was $60 \%$ which was the highest at 24 hours and 48 hours as compared to the control seeds which was $40 \%$ but at 96 hours seed germination percentage was equal for seeds treated with Silver Nanoparticles and normal water which was $60 \%$ [Fig.11 (a)]. The mean germination time was the highest at 96 hours for both control and Ag-Nanoparticles seeds. The seeds germination, mean germination time was lower for seeds treated with Ag-Nanoparticles as compared to control at 24 hours and 48 hours [Fig. 11 (b)]. The germination rate was high at 24 hours for both Ag-

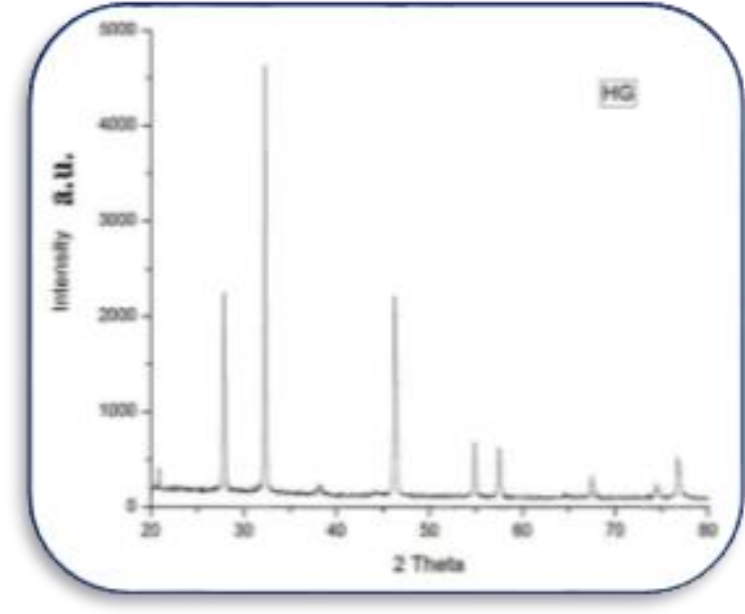

Fig. 8: Showing the XRD pattern of biosynthesized Ag-Nanoparticles.

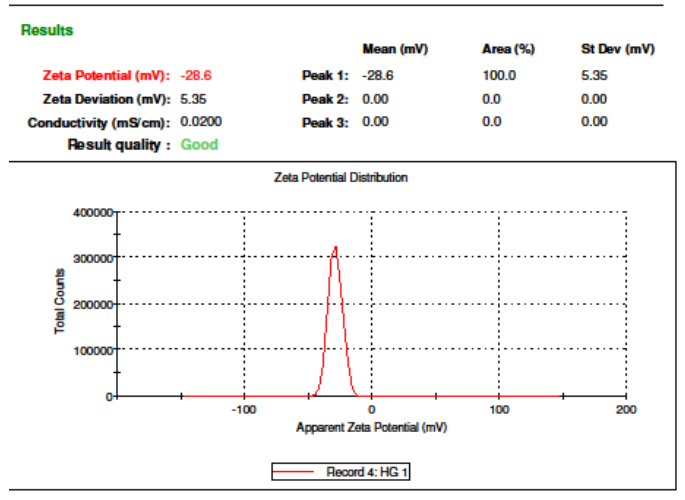

Fig. 10: Showing the Zeta potential of Ag-Nanoparticles.

Nanoparticles treated seeds and also controls. The germination rate was gradually decreased with time for both control and Ag-Nanoparticles treated seeds [Fig. 11 (c)]. The Abelmoschus seeds which were treated with AgNanoparticles had the highest germination index of 273.80 at 48 hours [Fig.11 (d)] and relative root elongation was gradually increased from 24 hours to 96 hours and the relative root elongation was 146.34 at 24 hours, 182.53 at 48 hours and 208.33 at 96 hours.

The seed germination time was minimum for normal water treated seeds in compared to the biosynthesized Ag-Nanoparticles treated seeds after 24, 48 and 96 hours of treatment [Fig. 11 (e) and (f)]. 
Effect of biosynthesized Silver Nanoparticles on seed germination of Abelmoschus esculentus:

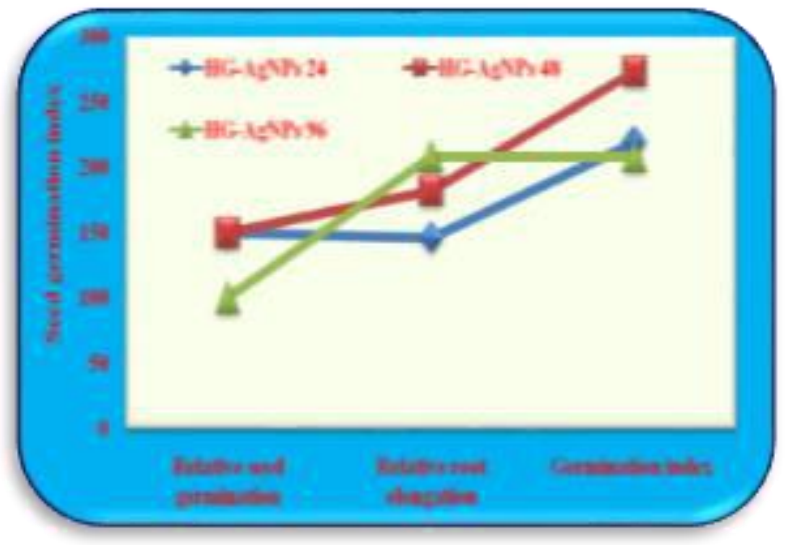

Fig. 11 (a): Showing seed germination. index.

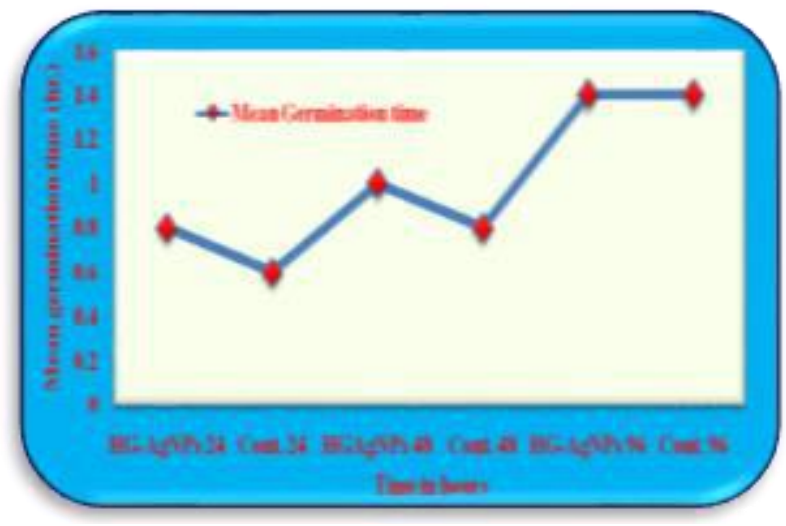

Fig. 11 (c): Showing mean seed germination time.

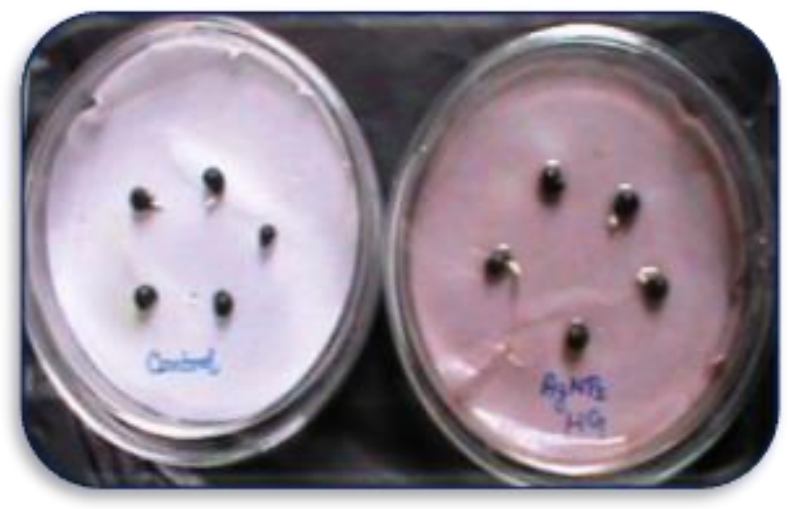

Fig. 11 (e): Showing seed germination.

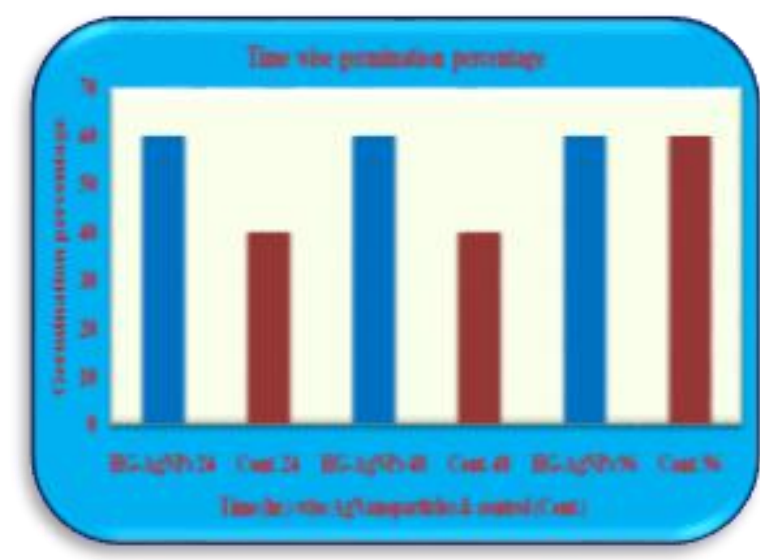

Fig. 11 (b): Showing seed germination. percentage.

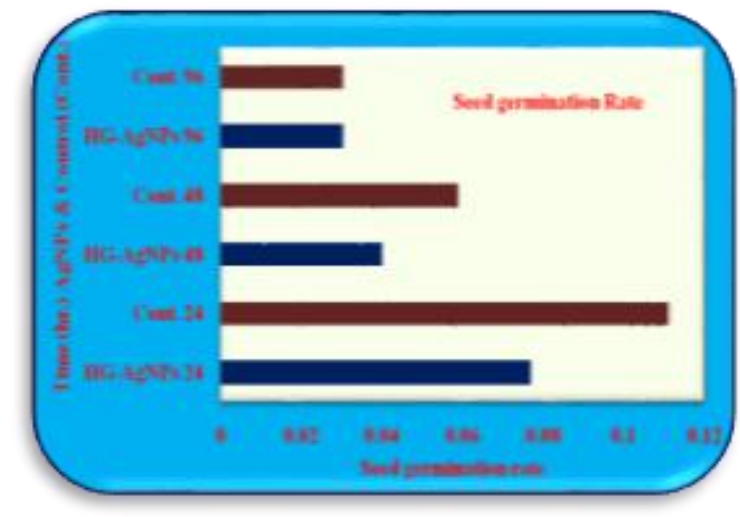

Fig. $11(d)$ : Showing seed germination rate.

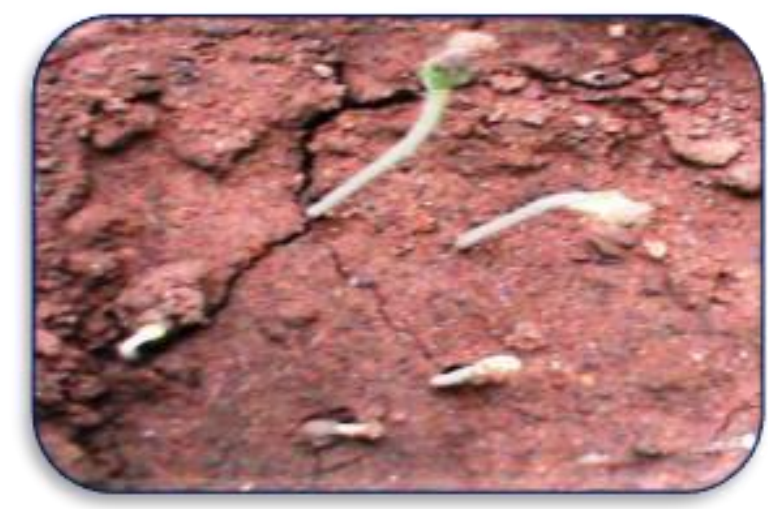

Fig. $11(f)$ : Showing seedling of ladies finger.

Effect of biosynthesized Ag-Nanoparticles on seed germination of Raphanus sativus var. longipinnatus:

For Raphanus sativus var. longipinnatus the seed germination index was 1466.66 which were the highest at 24 hours including the highest relative seed germination and relative root elongation, followed by germination index of 204.77 at 48 hours and 243.85 at 96 hours [Fig 12 (a)]. The germination percentage was $100 \%$ at 24, 48 and 96 hours, it indicated that all seeds were germinated with the treatment of seaweed synthesized Ag- Nanoparticles; but the germination percentage was $40 \%$ at 24 hours and $60 \%$ at 48 and 96 hours for the normal water treated seeds [Fig. 12 (b)]. The mean germination time was gradually increased with increase of incubation time; at 24 hours mean germination time was minimu m which indicated that germination rate was high at 24 hours for Ag-Nanoparticles treated seeds. The germination rate was 0.17 seed/hour and the seeds treated with Ag-Nanoparticles had maximum germination at 24 hours in comparison with normal water treated seeds [Fig. 12 (c), (d) (e), and (f)].

Effect of biosynthesized Silver Nanoparticles on seed germination of Raphanus sativus var. longipinnatus. 


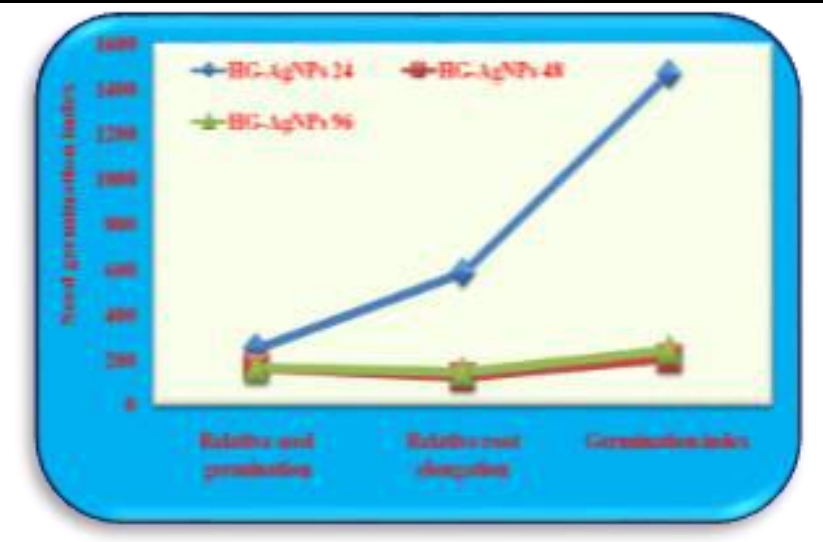

Fig. 12 (a): Showing seed germination index.

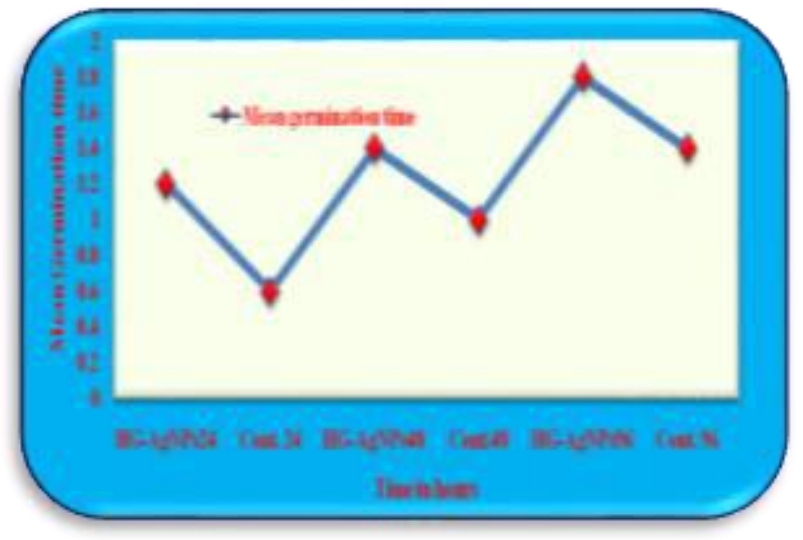

Fig. 12 (c): Showing mean seed germination time.

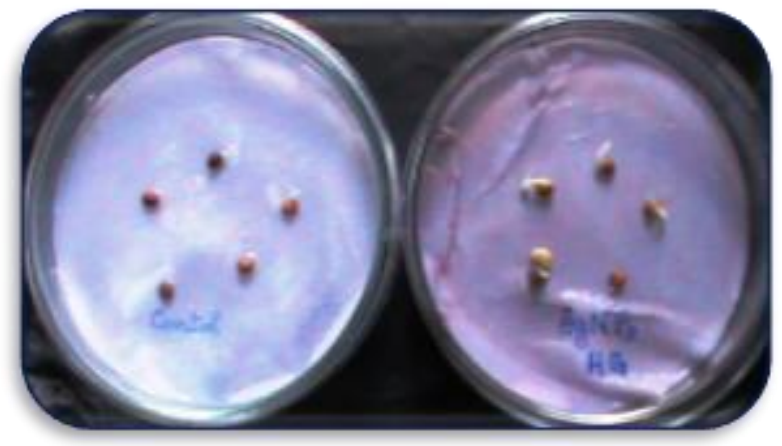

Fig. 12 (e): Showing seed germination.

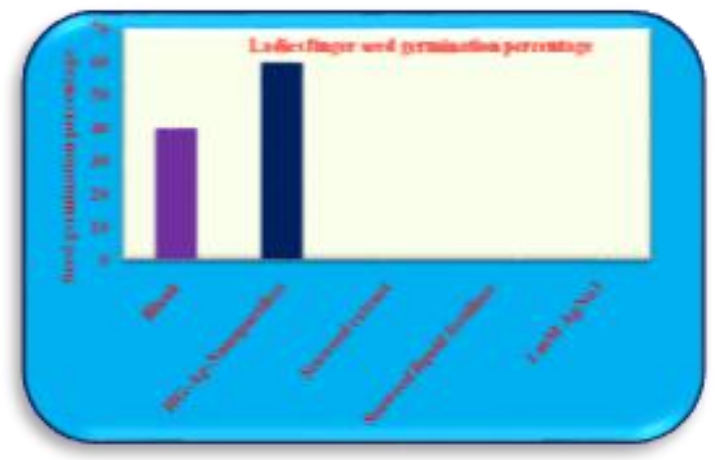

Fig. 13 (a): Showing seed germination percentage of ladies finger.

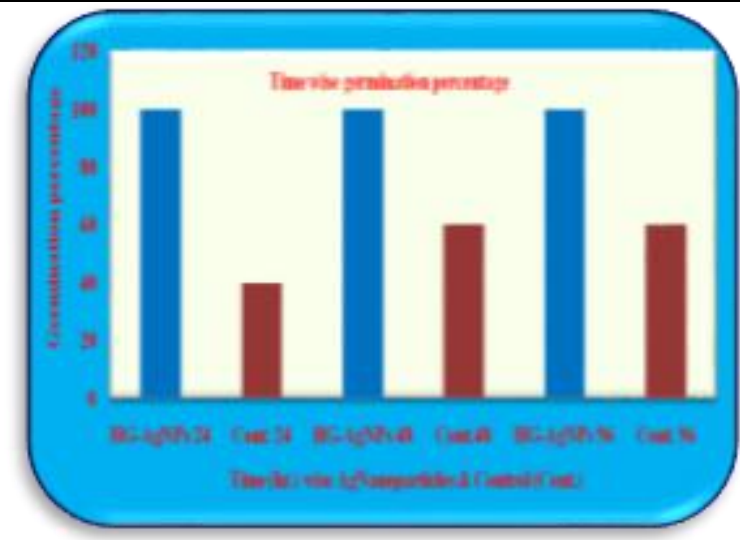

Fig. 12 (b): Showing seed germination percentage.

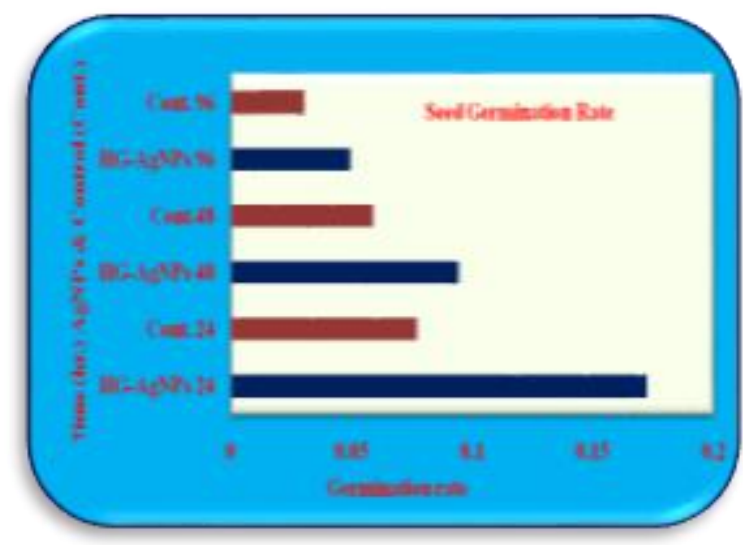

Fig. $12(d)$ : Showing seed germination rate.

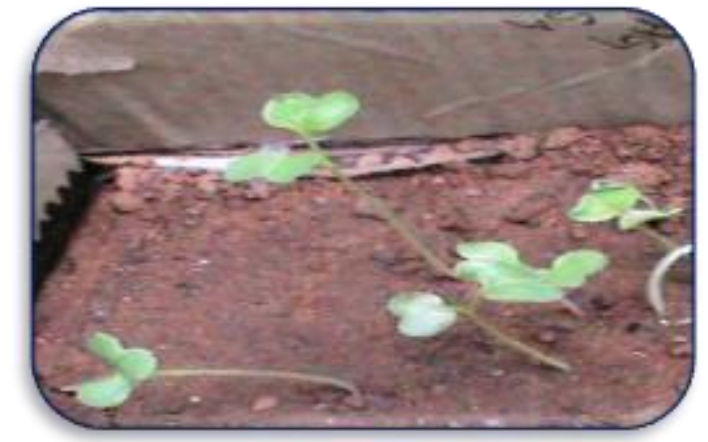

Fig. 12 (f): Showing seedling of radish.

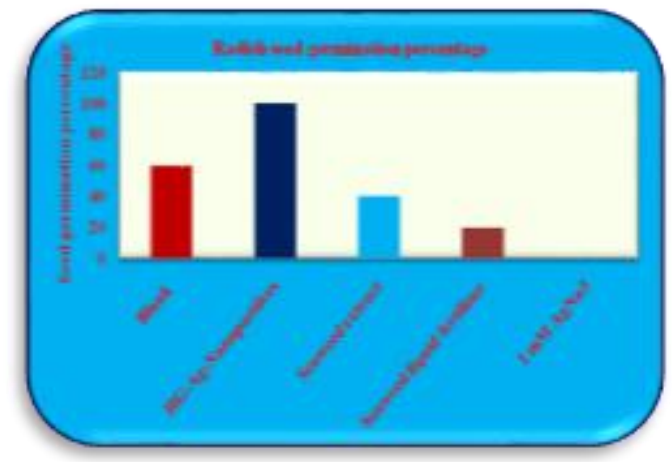

Fig. $13(b)$ : Showing seed germination percentage of radish. 
Effect of silver nitrate solution, seaweed liquid

fertilizer and seaweed extract on ladies finger and radish seed germination:

The $1 \mathrm{mM} \mathrm{AgNO}$ solution was used as negative control to test its effect on seed germination in comparison with normal water for both seeds and radish and ladies finger. The seed germination was $40 \%$ for ladies finger and $60 \%$ seeds of radish in normal water but no germination occurred for seeds treated with $1 \mathrm{mM}$ $\mathrm{AgNO}_{3}$ solution. It proved that $1 \mathrm{mM} \mathrm{AgNO} 3$ solution was toxic to both Abelmoschus and Raphanus seed germination. Both seeds were also treated with normal seaweed aqueous extract and seaweed liquid fertilizer of Halimeda gracilis for one week but no seeds germination occurred in case of the seeds treated with seaweed extract and seaweed liquid fertilizer for Abelmoschus but for Raphanus, $40 \%$ seeds germinated with the treatment of seaweed aqueous extract and 20\% seeds germinated with treatment of seaweed liquid fertilizer. The seeds treated with biosynthesized Silver Nanoparticles showed maximum germination and the growth of seedling which was better than normal water treated seeds and seaweed liquid bio-fertilizer and seaweed extract treated seeds [Fig. 13 (a) and (b)].

It had been previously reported that seaweed synthesized Ag-Nanoparticles by Sargassum cinctum had a quite good effect on Abelmoschus esculentus seed germination and the seedling growth. It had been reported that in comparing to normal water, seaweed AgNanoparticles had excellent potential for promoting seed germination and seedling growth (Roy et al. 2017).

Antibacterial activity of biosynthesized silver nanoparticles:

The inhibition of biosynthesized Silver Nanoparticles was $2.33 \pm 0.2 \mathrm{~cm}$ against Proteus mirabilis, $1 \pm 0.0 \mathrm{~cm}$ against Klebsiella pneumoniae which was high as compare to Ch loramphenicol $(5 \mathrm{mg} / \mathrm{ml})$ and silver nitrate solution (1 $\mathrm{mM})$. But the inhibition was less against Pseudomonas aeruginosa, Staphylococcus aureus, Escherichia coli, and Enterococcus faecalis (Fig. 14). Similarly, the biosynthesized Silver Nanopartic les by green seaweed Caulerpa prolifera had high antibacterial activity against Bacillus subtilis (Is mail et al. 2016).

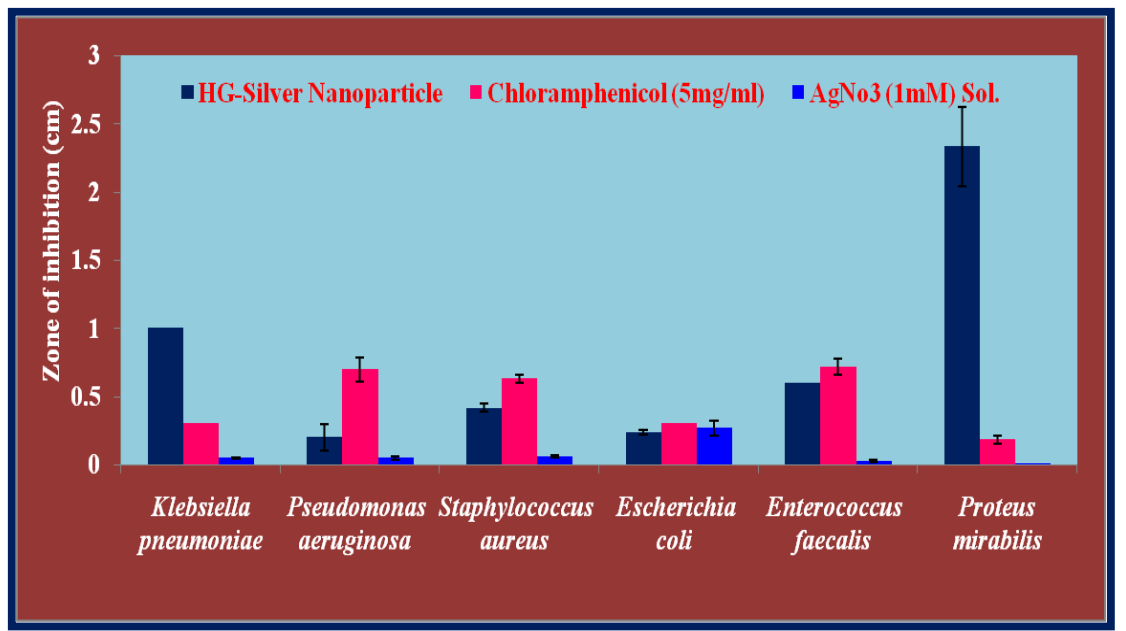

Fig. 14: Showing the zone of inhibition of biosynthesized Silver Nanoparticles (Halimeda gracilis), antibiotic and silver nitrate.

\section{CONCLUSIONS}

It can be concluded that the Ag-Nanoparticles of Halimeda gracilis showed the highest resistance against two pathogenic bacteria such as Klebsiella pneumoniae and Proteus mirabilis, so it may be used as a source of antibiotic production in future after further analysis. The Ag-Nanoparticles synthesized from Halimeda gracilis had maximum growth promoting effect and the highest seed germination in case of Raphanus sativus var. longipinnatus. It may be due to the easy penetration of Ag-Nanoparticles for its nano-size. The similar results were also found previously for the biosynthesized AgNanoparticles by Chaetomorpha antennina (Roy et al.
2017) and Amphiroa anceps (Roy et al. 2018). The biosynthesized Ag-Nanoparticles by Sargassum Ilicifolium (Roy et al. 2018) and Chlorodesmis hildebrandtii (Roy et al. 2018) also showed the same potential for seed germination of above mentioned both seeds. So, for circulation of nutrients and minerals very fast this nanosized particles are suitable, so, fast germination and the highest seedling growth was observed in case of both plants Abelmoschus esculentus and Raphanus sativus var. longipinnatus. In future, Ag-Nanoparticles will be used as phyto-friendly nano-bio fertilizer.

\section{ACKNOWLEDGEMENTS}


Authors sincerely thanks to Dr. Dr.

A. Saravanakumar. Authors are very much thankful for the kind help of Dr. P. Kumar, Assistant Professor, Department of Animal Health and Management 6th Floor, Science Campus, Alagappa University, Karaikudi. The authors are thankful to Dr. B. Shanthi and Dr. K. Siva Kumar at the Centralised Instrumentation and Service laboratory (CISL) at Department of Physics, Annamalai University for providing the Scanning Electron Microscopy and students of Dr. S. Kabilan, at Department of Physics for providing the FT-IR facility. Our sincere thank to the Dean and Director, Centre of Advanced Study in Marine Biology, Faculty of Marine Sciences, Annamalai University for proving the facilities to carry out this work successfully. Authors are also thankful to higher authorities of Annamalai University.

Conflict of interest: There are no conflicts of interest to be declared.

Funding: Authors are thankful to the Department of Science and Technology, Govt. of India for financial support.

\section{REFERENCES}

[1] Bhattacharya, S., (2006). ESBL-from Petri dish to the patient. Indian. J. Med. Microbiol., 24: 20-24

[2] Gandhi, H., and Khan, S., (2016). Biological Synthesis of Silver Nanoparticles and Its Antibacterial Activity. J Nanomed Nanotechnol, 7:2

[3] Gold, H. S. (2001). Vancomycin resistant, Enterococci: Mechanism and Clinical observations. Clin. Infect. Dis. 33: 210-219

[4] Kumar, P., Selvi, S. S., Govindaraju, M., (2013). Seaweed-mediated biosynthesis of Silver Nanoparticles using Gracilaria corticata for its antifungal activity against Candida spp. Appl Nanosci - 3: 495-500

[5] Pérez, M. J., Falqué, E., and Domínguez, H., (2016). Antimicrobial Action of Compounds from Marine Seaweed, Mar. Drugs, 14, 52

[6] Barrena, R. E. Casals, J. Colon, X. Font, A. Sanchez and V. Puntes, (2009). Evaluation of the Ecotoxicity of model Nanoparticles. Chemosphere, 75 (7): 850857.

[7] Roy, S., and Anantharaman, P. (2017). Green Synthesis of Silver Nanoparticles by Sargassum Cinctum J. Agardh and their Potential for Seed Germination, International Journal of Trend in Scientific Research and Development (IJTSRD), ISSN No: 2456 - 6470 , Volume - 1, Issue-5

[8] Roy S, Anantharaman P (2018). Biosynthesis of Silver Nanoparticles by Sargassum Ilicifolium
(Turner) C. Agardh with their antimicrobial activity and potential for seed germination. Journal of Applied Physics \& Nanotechnology 1: 1-9.

[9] Sivasangari Ramya, S., Vijayanand, N., Rathinavel, S., (2015). Foliar application of liqu id bio-fertilizer of brown alga Stochiospermum marginatum on growth, biochemical and yield of Solanum melongena. Int. J. Recycl Org. Waste Agricult. 4: 167-173

[10] Taga, M. S. Miller, E. E. D. E. and Pratt, (1984). Chia seeds as a source of natural lipids antioxidants. J Am Oil Chem Soc. 61(5): 928-993.

[11] Thakkar, K. N. Mhatre, S. S and Parikh, R. Y. (2010). Biological synthesis of metallic nanoparticles. Nanomedicine, 6(2): 257-262.

[12] Vivek, M., Kumar, P. S., Steffi, S., and Sudha, S., (2011). Biogenic Silver Nanoparticles by Gelidiella acerosa Extract and their Antifungal Effects, Avicenna J Med Biotechnol. 3(3): 143-148.

[13] Roy, S. and Anantharaman, P. (2018). Biosynthesis of Silver Nanoparticles by Amphiroa anceps (Lamarck) Decaisne and Its Biomedical and Ecological Implications. Journal of Nanomedicine and Nanotechnology, 9(2), pp: 2-5.

[14] Roy, S. and Anantharaman, P. (2017). Biosynthesis of Silver Nanoparticles by Chaetomorpha antennina (Bory de Saint-Vincent) Kutzing with its antibacterial activity and ecological implication. Journal of Nanomed icine and Nanotechnology, 8(5), pp: 2-9.

[15] Roy, S. and Anantharaman, P. (2018). Biosynthesis of Silver Nanoparticles by Chlorodesmis Hildebrandtii A. Gepp \& E. Gepp Including its Agricultural and Biomedical Implications Nanomed Nanotechnol Biosynthes is of Silver Nanopartic les by Chlorodesmis Hildebrandtii A. Gepp \& E. Gepp Including its Agricultural and Biomedical Implications. Nanomedicine \& Nanotechnology, 3(3), pp: 1-9.

[16] Ganesapandian, S. Manikandan, S. Singh, M. and Kumaraguru, A. K. (2011). Emerging of multidrug resistance human pathogens from Urinary tract infections. Current Research in Bacteriology, 4 (1): 9-15.

[17] Ismail, Y. Wedyan, M. Al-Zuabe, M. and Abdurrahman, S., (2016). Antimicrobial activity of Rubia cordifolia: methods to determine antimicrobial activity. Research journal of Medicinal Plants: 10 (8): 457-462. 